\title{
DEXMEDETOMIDINE AS A SOLE ANAESTHETIC AGENT IN NEUROSURGICAL PROCEDURES
}

\author{
Kolati Vara Lakshmi Suneetha1, Pabba Upender Gowd², Kakarla Swarna Latha ${ }^{3}$
}

${ }_{1}^{1}$ Assistant Professor, Department of Anaesthesiology, Rangaraya Medical College, Kakinada, Andhra Pradesh, India.

2Former Professor and HOD, Department of Anaesthesiology, Gandhi Medical College, Secunderabad, Telangana, India.

3Professor, Department of Pharmacology, Andhra Medical College, Visakhapatnam, Andhra Pradesh, India.

\section{BACKGROUND}

\section{ABSTRACT}

Dexmedetomidine is an alpha-2 agonist gaining popularity in neurosurgery due to its unique properties as a sedative, anxiolytic and anaesthetic sparing effects without respiratory depression. We designed this study to assess the efficacy of Dexmedetomidine as a sole anaesthetic agent in neurosurgical cases lasting less than 90 min on spontaneous ventilation.

\section{METHODS}

After ethical committee approval and informed consent, adult patients of either gender ASA 1 or 2 of age group 18-60 years undergoing neurosurgical procedures lasting less than $90 \mathrm{~min}$ were included. All patients received standardized premedication and induced with IV Inj Fentanyl $2 \mathrm{mcg} / \mathrm{kg}$ and Inj. Dexmedetomidine bolus $1 \mathrm{mcg} / \mathrm{kg}$ (Over $10 \mathrm{~min}$ ). All patients were put on Hudson's face mask on spontaneous ventilation with $4 \mathrm{~L} / \mathrm{min}$ oxygen. All patients maintained only with Inj. Dexmedetomidine infusion at 0.4$0.7 \mathrm{mcg} / \mathrm{kg} / \mathrm{hr}$ titrated to response Parameters- Haemodynamics, Post Induction sedation scores, Blood glucose, Patient movement at various stimuli, postoperative SOCA scores, analgesic requirement for the first $6 \mathrm{hrs}$ after surgery were noted. Data collected accordingly.

\section{RESULTS}

There was a statistically significant fall in the heart rate, systolic, diastolic and mean blood pressure (p-0.000) during infusion of Dexmedetomidine. There was no reduction in arterial oxygen saturation, no significant change in blood glucose ( $p-0.900)$. There were eight events of movement during the procedure requiring administration of fentanyl. Recovery of all patients was good. The mean SOCA score was $8.7 \pm 1.4$. Incidence of PONV and need for rescue analgesia were not there in most of the patients.

\section{CONCLUSIONS}

Dexmedetomidine was found to be a good to excellent sole anaesthetic agent in short neurosurgical procedures.

HOW TO CITE THIS ARTICLE: Suneetha KVL, Gowd PU, Latha KS. Dexmedetomidine as a sole anaesthetic agent in neurosurgical procedures. J. Evolution Med. Dent. Sci. 2019;8(16):1287-1290, DOI: 10.14260/jemds/2019/287

\section{BACKGROUND}

Dexmedetomidine is an alpha-2 agonist gaining popularity in neurosurgery due to its unique properties as a sedative, anxiolytic and anaesthetic sparing effects without respiratory depression. $\alpha 2$-adrenergic receptor ( $\alpha 2$-AR) agonists have been successfully used in several clinical settings in view of diverse actions which include sedation, analgesia, anxiolysis, perioperative sympatholysis, cardiovascular stabilizing effects, reduced anaesthetic requirements, and preservation of respiratory function.[1] Dexmedetomidine was approved in 1999 by the US Food and Drug Administration (FDA) as a short-term sedative and analgesic $(<24$ hours) for critically ill or injured people on mechanical ventilation in the intensive care unit (ICU). The rationale for its short-term use was due to concerns over withdrawal side effects such as rebound high blood pressure.[2] Locus ceruleus of the brain stem is the principal site for the sedative action and spinal cord is the principal site for the analgesic action, both acting through $\alpha 2 \mathrm{~A}$ $\mathrm{AR}$. In the heart the dominant action of $\alpha 2$-AR agonists is decrease in tachycardia (Through blocking cardioaccelerator

'Financial or Other Competing Interest': None.

Submission 27-02-2019, Peer Review 10-04-2019,

Acceptance 16-04-2019, Published 22-04-2019.

Corresponding Author:

Dr. Kakarla Swarna Latha,

3-16-185, Sri Vidya Colony,

Godari Gunta, Kakinada,

EGDT, Andhra Pradesh, India.

E-mail: drkswarna@yahoo.com

DOI: $10.14260 /$ jemds/2019/287 nerve) and bradycardia via $\alpha 2 \mathrm{~A}-\mathrm{AR}$ (Through a vagomimetic action).[3] Dexmedetomidine is a new intravenous drug gaining popularity in neuro-anaesthesia and neurocritical care practice. This alpha 2-adrenergic receptor agonist offers a unique "cooperative sedation," anxiolysis, analgesia and anaesthetic sparing effects with no respiratory depression.[4] Cerebral effects are generally consistent with a desirable neurophysiological profile, including neuroprotective characteristics. In addition, sympatholytic and antinociceptive properties allow for hemodynamic stability at critical moments of neurosurgical stimulation. Sympatholysismediated vasodilatation and smooth muscle cells receptormediated vasoconstriction [4]. The responses to activation of the receptors in other areas include decreased salivation, decreased secretion, and decreased bowel motility in the gastrointestinal tract; contraction of vascular and other smooth muscle; inhibition of renin release, increased glomerular filtration, and increased secretion of sodium and water in the kidney; decreased intraocular pressure; and decreased insulin release from the pancreas. Combining all these effects, dexmedetomidine avoids some of the side effects of multi agent therapies.

Dexmedetomidine reduces cerebral blood flow and cerebral metabolic requirement of oxygen but its effect on intracranial pressure (ICP) is not yet clear. Dexmedetomidine modulates spatial working memory, enhancing cognitive performance besides having sedative, analgesic, and anxiolytic action through the $\alpha 2$-AR.[5] Studies suggest the likelihood of its neuroprotective action by reducing the levels of circulating $\&$ brain catecholamines and thus balancing the ratio between 
cerebral oxygen supplies, reducing excitotoxicity, and improving the perfusion in the ischemic penumbra. It reduces the levels of the glutamate responsible for cellular brain injury, especially in subarachnoid haemorrhage[ ${ }^{6]}$ It has been shown to limit the morphologic and functional effects after ischemic (focal and global) traumatic injury to the nervous system We designed this study to assess the efficacy of Dexmedetomidine as a sole anaesthetic agent in neurosurgical cases lasting less than 90 min on spontaneous ventilation.

\section{METHODS}

After Institutional ethical committee approval and informed consent, twenty-six adult patients of either gender, ASA 1 or 2 scheduled for elective neurosurgical cases lasting less than 90 min are included in the study. All patients received standardized premedication. All patients induced with Intravenous Fentanyl $2 \mathrm{mcg} / \mathrm{kg}$ and Inj. Dexmedetomidine bolus $1 \mathrm{mcg} / \mathrm{kg}$ (Over $10 \mathrm{~min}$ ).All patients were put on Hudson's face mask on spontaneous ventilation with $4 \mathrm{~L} / \mathrm{min}$ oxygen. All patients were maintained only with Inj. Dexmedetomidine infusion at $0.4-0.7 \mathrm{mcg} / \mathrm{kg} / \mathrm{hr}$ titrated to response. Parameters, noted are Post induction sedation scores, Haemodynamics (Heart rate, ECG, systolic, diastolic, mean Blood pressure, oxygen saturation) Blood glucose, patient movement at various stimuli, postoperative SOCA scores, analgesic requirement for the first $6 \mathrm{hrs}$. after surgery were noted.

\section{Type of Study}

Prospective interventional study.

\section{Inclusion Criteria}

Age group of 18- 60 years; belonging to either gender, ASA 1 and 2.

\section{Exclusion Criteria}

Ischemic heart disease, Renal or hepatic disease, Hypovolemic or Hypovolemic patients, Patients on diuretics or cardioactive drugs interfering with haemodynamic responses.

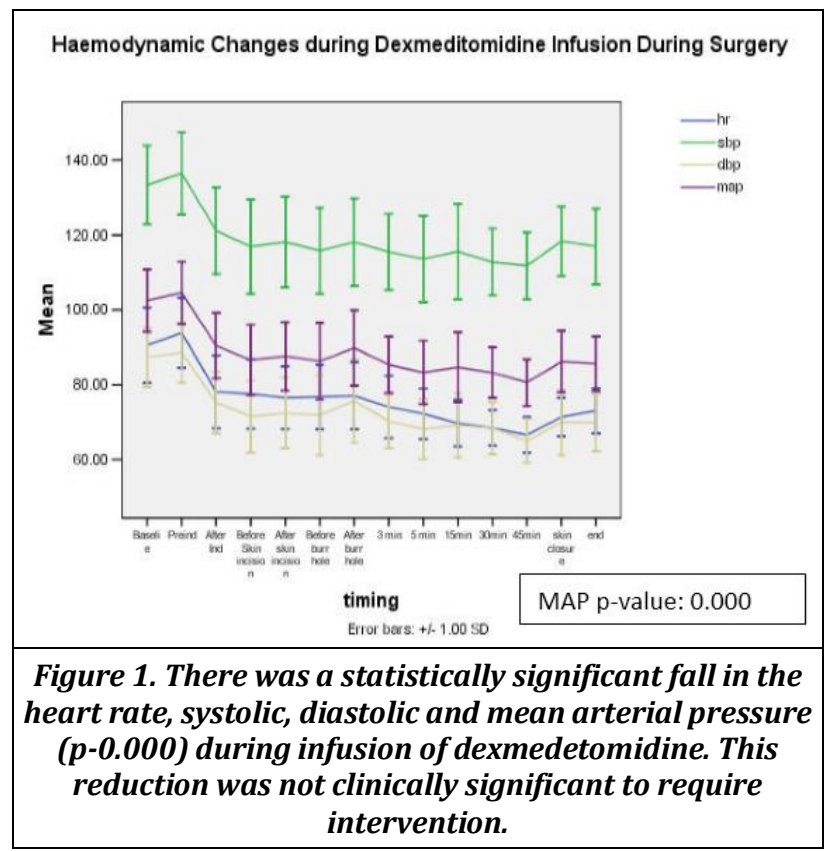

\section{Statistical analysis}

Statistical analysis was performed by using SPSS version 13. Descriptive statistics are expressed as Mean with S.D. for continuous data and frequency with percentage for categorical data. Comparison of baseline values of haemodynamics, oxygen saturation and blood glucose with the intraoperative values was performed using ANOVA with post-hoc analysis using Dunnett's test. Comparison of baseline values of haemodynamics, oxygen saturation and blood glucose with the intraoperative values was performed using ANOVA with posthoc analysis using Dunnett's test.

\section{RESULTS}

All patients received standard premedication and induced with Intravenous Fentanyl $2 \mathrm{mcg} / \mathrm{kg}$ and Inj. Dexmedetomidine bolus $1 \mathrm{mcg} / \mathrm{kg}$ (over $10 \mathrm{~min}$ ). All patients were put on Hudson's face mask on spontaneous ventilation with $4 \mathrm{~L} / \mathrm{min}$ oxygen. All patients were maintained only with Inj. Dexmedetomidine infusion @ 0.4-0.9 mcg/ $/ \mathrm{kg} / \mathrm{hr}$ titrated to response. There was a statistically significant fall in the heart rate, systolic, diastolic and mean arterial pressure ( $p$ 0.000) during infusion of dexmedetomidine (Fig. 1). This reduction was not clinically significant to require intervention for management in any of the patients. There was no reduction in arterial oxygen saturation in any of the patients (Fig. II). There was no significant change in blood glucose (p-0.9) (Fig. III).There were eight events of movement during the procedure requiring administration of fentanyl. The recovery of all patients was good. The mean SOCA score was $8.7 \pm 1.4$. Post induction sedation scores (Fig. IV), Haemodynamics (Heart rate, ECG, systolic, diastolic, mean arterial blood pressure, oxygen saturation), blood glucose, patient movement at various stimuli, postoperative SOCA scores (Fig. $\mathrm{V}$ ), analgesic requirement for the first $6 \mathrm{hrs}$ after surgery were noted. Post-opera tive nausea and vomiting (Fig. VI) and need for rescue analgesia (Fig. VII) were noted.

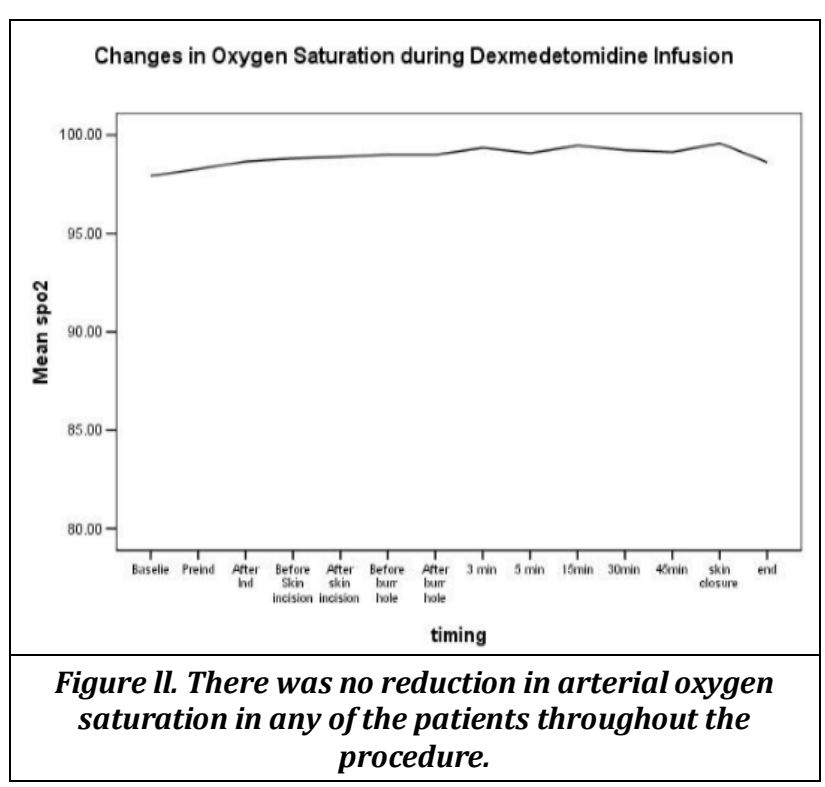




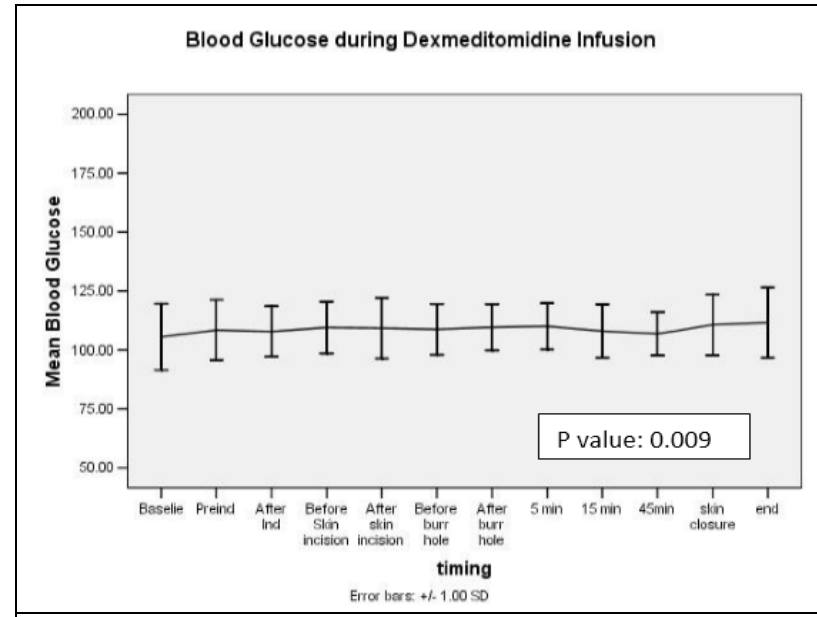

Figure III. Blood Glucose Changes with Dexmedetomidine There was no significant change in blood glucose $(p=0.900)$.
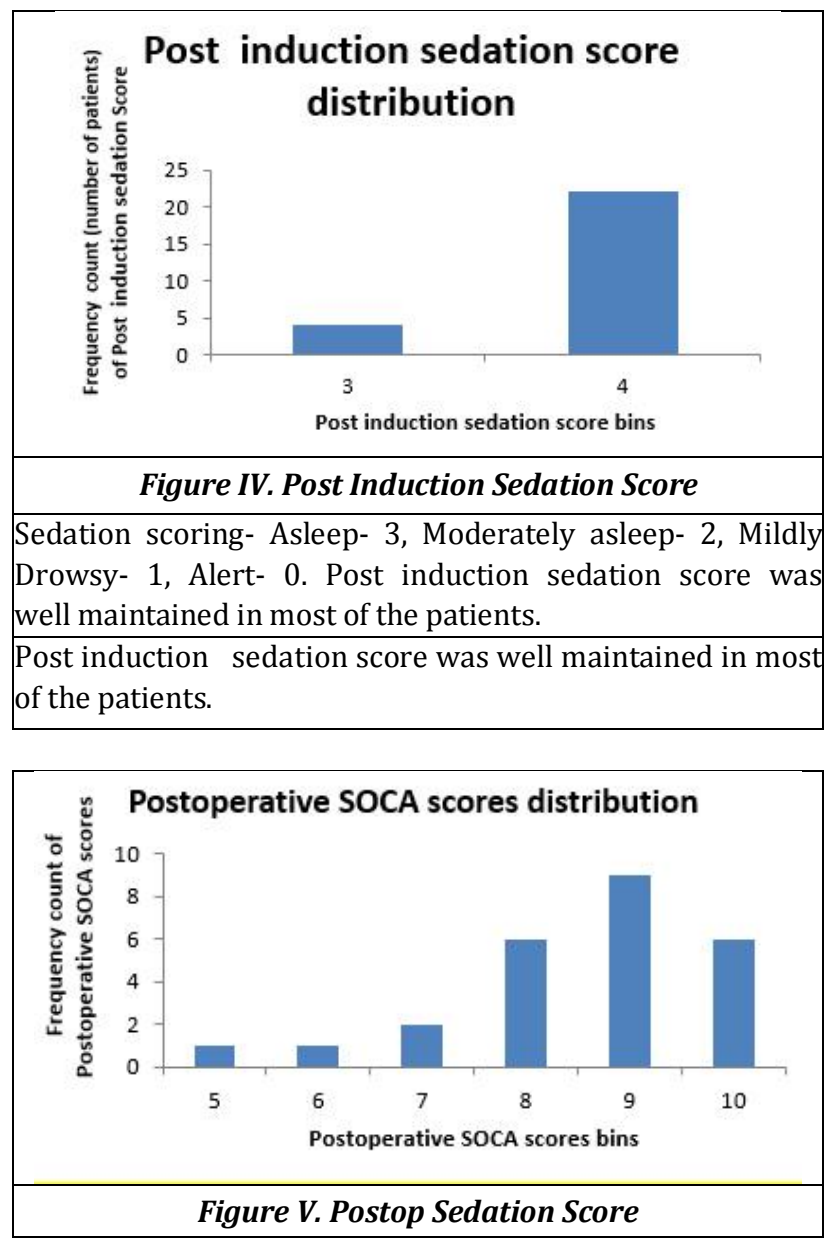

Postoperative sedative score was good in most of the patients. Mean SOCA score was $8.7 \pm 1.4$

\section{DISCUSSION}

Dexmedetomidine reduces cerebral blood flow and cerebral metabolic requirement of oxygen. Dexmedetomidine modulates spatial working memory, enhancing cognitive performance besides having sedative, analgesic, and anxiolytic action through the $\alpha 2$-AR. [3] Studies suggest the likelihood of its neuroprotective action by reducing the levels of circulating and brain catecholamines and thus balancing the ratio
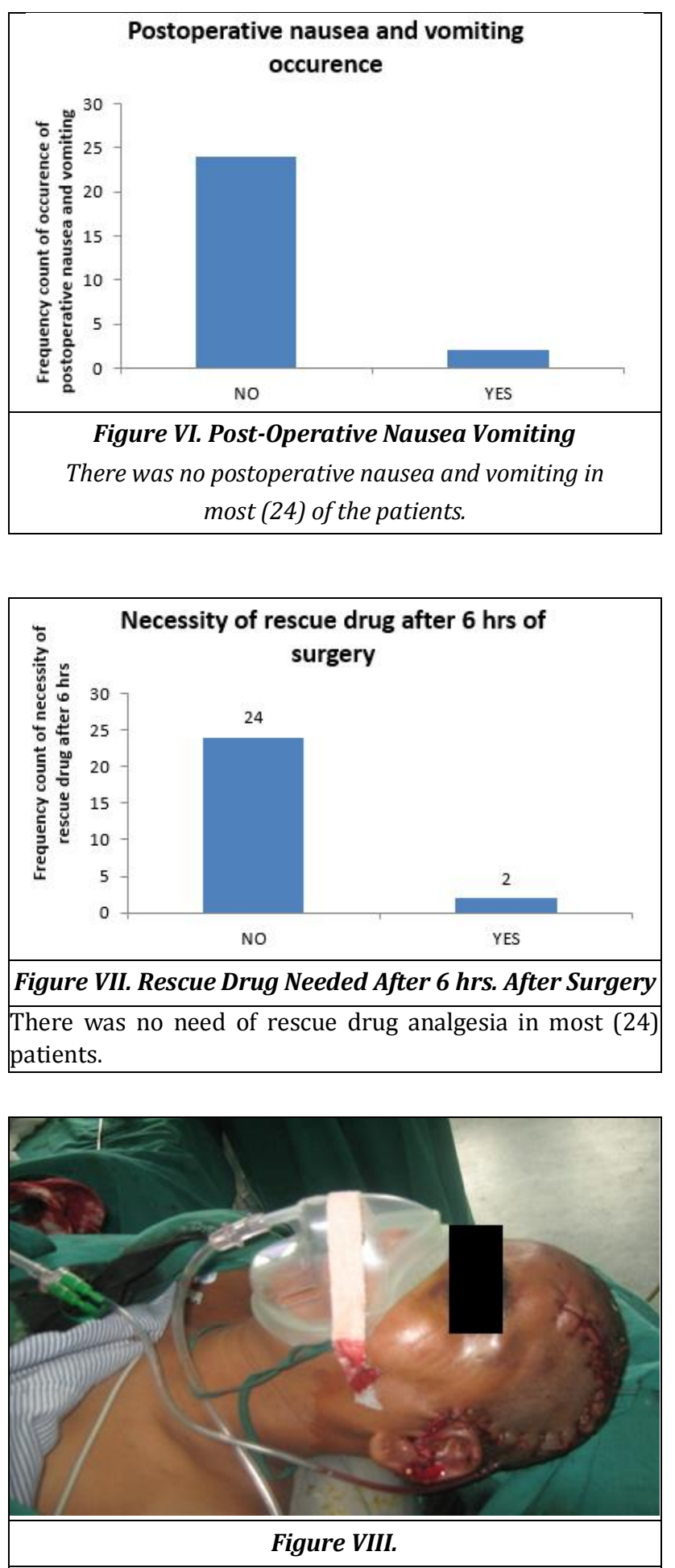

Picture taken after the procedure. Patient tolerated the procedure very well, calm and comfortable without any respiratory problems and well maintained haemodynamics.

between cerebral oxygen supplies, reducing excitotoxicity, and improving the perfusion in the ischemic penumbra. It reduces the levels of the glutamate responsible for cellular brain injury, especially in subarachnoid haemorrhage.[7] It has been shown to limit the morphologic and functional effects after ischemic (focal and global) and traumatic injury to the nervous system assessed by Post induction sedation scores, oxygen saturation) 


$\begin{array}{ll}\text { Sedation Scoring } & \\ \text { Asleep } & 3 \\ \text { Moderately Asleep } & 2 \\ \text { Mildly Drowsy } & 1 \\ \text { Alert } & 0\end{array}$

There was a statistically significant fall in the heart rate, systolic, diastolic and mean arterial pressure ( $p-0.000)$ Fig. I this is in agreement with Bloor BC and others study where iv dexmedetomidine causes haemodynamic changes maximum decrease in MABP at $60 \mathrm{~min}$ of $14 \%, 16 \%, 23 \%$, and $27 \%$ for the $0.25,0.5,1.0$, and 2.0 micrograms/kg groups, respectively $(\mathrm{P}<.05)$. At 330 min MABP remained below baseline by $8 \%$ and $17 \%$ at the two largest doses $(\mathrm{P}<.05)$. Both HR and CO decreased maximally by both $17 \%$ at 105 min during infusion of dexmedetomidine. ${ }^{\{8\}}$ Oxygen saturation Fig. II was decreased with dexmedetomidine in other studies, but it is good in our study. Blood glucose, was reduced but statistically not significant. This agrees with other study JOHN WALKERS showed the reduction which is also not statistically significant. $\left.{ }^{9}\right\}$ Fig. III. This reduction was not clinically significant to require intervention for management in any of the patients.

Movement at stimuli, patient movement at various stimuli only 8 times during the administration of fentanyl also similar to Sharifuddine and his colleagues study and proved that with dexmedetomidine use intraoperative anaesthetic use is decreased. There was a low incidence of movement during the procedure.\{10\} (Fig. IV) Postoperative SOCA scores (postoperative period, sedation, orientation, comprehension and amnesia)

\section{Postoperative Sedative And Recovery Scores}

\section{Sedation}

Awake and alert or tense: $\quad 4$

Awake and not alert: $\quad 3$

Drowsy: 2

Asleep: 1

Asleep and not arousable: $\quad 0$

\section{Orientation}

Fully oriented:

Partial disorientation:

Total disorientation:

\section{Comprehension}

Execution of order:

Execution of order only by initiation: 1

No execution of order:

4
3
2
1
0

(1)

$\begin{array}{ll}\text { Amnesia } & \\ \text { No Amnesia: } & 3 \\ \text { Slight amnesia: } & 2 \\ \text { Moderate amnesia: } & 1 \\ \text { Severe amnesia: } & 0\end{array}$

The mean SOCA score was $8.7 \pm 1.4$. These values are suggestive of study by Myriam Bellot and Alex Le Bot. We followed sedation scale (Fig. IV) and noted. Postoperatively, patients were assessed in the Post Anaesthesia Care Unit (PACU) within the hour for sedation levels, pain intensity (On Visual Analogue Score, VAS 0-10), incidence of nausea and vomiting. Fig. $\mathrm{V}$ need for rescue analgesia Analgesic requirement for the first 6 hrs. after surgery were Fig. VII with dexmedetomidine Post induction score, postoperative sedation score were good with no rescue analgesia and there was no postoperative nausea and vomiting. $\{9\}$

There was no reduction in arterial oxygen saturation in any of the patients. The recovery of all patients was good. The usage of Dexmedetomidine was found to be excellent in maintenance of hemodynamic, oxygen saturation, blood glucose intraoperatively. There was a low incidence of movement during the procedure. Post induction score, postoperative sedation score were good with no rescue analgesia and there was no postoperative nausea and vomiting.

\section{CONCLUSIONS}

Dexmedetomidine was found to be a good to excellent sole anaesthetic agent in short neurosurgical procedures.

\section{REFERENCES}

[1] Kemp KM, Henderlight L, Neville M. Precedex: Is it the future of cooperative sedation? Nursing 2008;38(Suppl Critical):7-8.

[2] Takrouri MS, Seraj MA, Channa AB, et al. Dexmedetomidine in intensive care unit: A study of hemodynamic changes. Middle East J Anesthesiol 2002;16(6):587-95.

[3] Takrouri MS. New concepts in intensive care: dexmedetomidine and immunonutrition. Middle East J Anesthesiol 2002;16(6):567-72.

[4] Dexmedetomidine. [Last accessed on 2011 March 18]. http://en.wikipedia.org/wiki/Dexmedetomidine.

[5] Franowicz JS, Arnsten AF. The alpha-2a noradrenergic agonist, guanfacine, improves delayed response performance in young adult rhesus monkeys. Psychopharmacology (Berl) 1998;136(1):8-14.

[6] Bekker A, Sturaitis MK. Dexmedetomidine for neurological surgery. Neurosurgery 2005;57(1 Suppl):1-10.

[7] Bellon M, Le Bot A, Michelet D, et al. Efficacy of intraoperative dexmedetomidine compared with placebo for postoperative pain management: a metaanalysis of published studies. Pain Ther 2016;5(1):6380.

[8] Ramsay MA, Savege TM, Simpson BR, et al. Controlled sedation with alphaxalone-alphadolone. $\mathrm{Br}$ Med J 1974;2(5920):656-9.

[9] Bloor BC, Ward DS, Belleville JP, et al. Effects of intravenous dexmedetomidine in humans. II. Hemodynamic changes. Anesthesiology 1992;77(6):1134-42.

[10] Cetin M, Birbicer H, Hallioglu O, et al. Comparative study between the effects of dexmedetomidine and propofol on cerebral oxygenation during sedation at pediatric cardiac catheterization. Ann Card Anaesth 2016;19(1):20-4.

[11] Jarineshin H, Fekrat F, Kermanshah KA. Treatment of postoperative pain in pediatric operations: comparing the efficiency of bupivacaine, bupivacainedexmedetomidine and bupivacaine-fentanyl for caudal block. Anesth Pain Med 2016;6(5): e39495. 